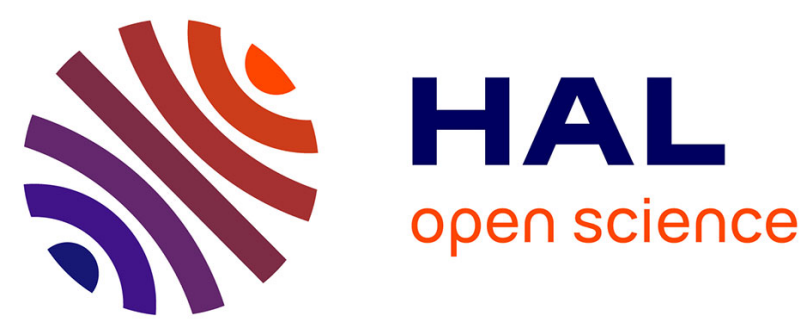

\title{
Supporting Sustainability Through Collaborative Awareness Raising - A Case of Sri Lankan Telecentres
}

Sirkku Männikkö-Barbutiu, Harsha Perera, Upul Anuradha, Ranil Peiris, Thomas Westin

\section{To cite this version:}

Sirkku Männikkö-Barbutiu, Harsha Perera, Upul Anuradha, Ranil Peiris, Thomas Westin. Supporting Sustainability Through Collaborative Awareness Raising - A Case of Sri Lankan Telecentres. 14th International Conference on Social Implications of Computers in Developing Countries (ICT4D), May 2017, Yogyakarta, Indonesia. pp.410-421, 10.1007/978-3-319-59111-7_34 . hal-01650069

\section{HAL Id: hal-01650069 \\ https://hal.inria.fr/hal-01650069}

Submitted on 28 Nov 2017

HAL is a multi-disciplinary open access archive for the deposit and dissemination of scientific research documents, whether they are published or not. The documents may come from teaching and research institutions in France or abroad, or from public or private research centers.
L'archive ouverte pluridisciplinaire HAL, est destinée au dépôt et à la diffusion de documents scientifiques de niveau recherche, publiés ou non, émanant des établissements d'enseignement et de recherche français ou étrangers, des laboratoires publics ou privés. 


\title{
Supporting Sustainability through Collaborative Awareness Raising - A Case of Sri Lankan Telecentres
}

\author{
Sirkku Männikkö-Barbutiu ${ }^{1 \rrbracket}$, Harsha Perera ${ }^{2}$, Upul Anuradha ${ }^{2}$, Ranil Peiris ${ }^{1}$, and \\ Thomas Westin ${ }^{1}$ \\ ${ }^{1}$ Stockholm University, Department of Computer and Systems Science, Kista, Sweden \\ \{sirkku, ranil, thomaswedsv.su.se \\ ${ }^{2}$ University of Colombo, School of Computing, Colombo, Sri Lanka \\ $\{h d p$, uar@ucsc.cmb.ac.lk\}
}

\begin{abstract}
For the development of sustainable ICT services, participation of the local communities is crucial. A meaningful involvement requires awareness and understanding of the various possibilities of the ICTs. In this paper, the processes of awareness raising among underprivileged population in the Sri Lankan tea estate district of Nuwara Eliya are examined, drawing on the findings from an empirical study conducted at two telecentres. A specific participatory methodology, where co-inspirational sessions and brainstorming constituted main activities of co-creation of knowledge was applied. Our empirical data confirms that the participatory methods can trigger curiosity and engagement among participants. Ideas and suggestions that emerged during brainstorming demonstrate relevance, realism as well as they are a proof of real needs and requirements of a population that lives under difficult conditions in remote locations. Participatory methods can initiate community engagement for a longstanding, sustainable transformation of the TCs, in collaboration with ICT developers, and TC staff.
\end{abstract}

Keywords: Workshops $\bullet$ Participatory Methodology $\bullet$ Telecentres $\bullet$ ICT diffusion • Sustainability

\section{Introduction}

Telecentres (TCs) as access points and training facilities to ICTs and the Internet constitute an important strategy in many present day countries in Africa and Asia. In ICT4D research literature, the potential of TCs as central in providing education and other government services in rural areas is discussed $[3,15,17,21]$ recognising the role of TCs as central in endeavours of ICT diffusion and implementation in societies.

Even though there seems to exist a wide consensus among policy makers of the relevance of TCs $[4,6,9,18]$, sustainability of these establishments can be questioned, if their existence and operations are not well-grounded in the local community [14]. With well-grounded we mean both awareness of the possibilities of ICTs among the local population and awareness of the local needs and requirements among the researchers and developers. By emphasizing the importance of social embeddedness and the context-specific meaning making and practices, we, the authors of this paper, position 
ourselves in the field of progressive transformation, where the aim is to create socioeconomic improvements with the help of ICTs through locally situated action[1, 7, 8]. As Hanna [7] points out, the centrally driven programs often lack strategies to promote local, bottom-up initiatives to build capacity at grass root level and to create innovative partnerships, which all are critical in supporting local knowledge and capabilities for achieving scalability and sustainability. Instead, a lot of initiatives have the characteristics of hierarchical orderings of a techno-state with top-down approach to development [24]. Heeks [11] outlines good practices for successful ICT in development projects, in three main categories: 1) Actors and Governance (stakeholders and open, competitive environment); 2) Sustainable projects (financial and social sustainability, local ownership); and 3) Design techniques (local participation, appropriate technologies, local development goals, and project risks).

Despite the criticism directed towards TCs as outdated in the modern era of smartphones, we believe that TCs still have an important role to play in the remote, disadvantaged areas, where the population lives with limited or no access to the ICTs and where the educational institutions fail to provide adequate training in the use of these technologies. Even if the population may have access to mobile phones, these are often of simple standard without functionalities needed for elaborate e-learning activities, for example. Our previous studies in Sri Lanka [20] confirm the existence of a wide digital divide between the urban and rural areas. The remote tea estate population distinguishes as particularly disadvantaged regarding computer literacy with only $9 \%$ of the population over ten years of age being computer literate. The corresponding figure for the rural population is $25.5 \%$ and for the urban one $39.2 \%$ [5].

The purpose of this paper is to discuss the issue of awareness raising through a case study conducted in two TCs at the tea estate district Nuwara Eliya in the central hill country of Sri Lanka. We draw on empirical data from a field study that employed a set of collaborative methods with the goal of engaging the local community in the development of their TC.

\subsection{Problem and Research Questions}

The government initiated nationwide e-Sri Lanka and the TC (Nenasala) projects [23] can be described as typical top-down endeavours of a techno-state, where the local involvement is limited. Inauguration of a TC with a big cultural celebration in the presence of political leadership being the only (official) awareness raising activity, many people have only a vague idea of the possibilities of TCs, which may partly explain the low engagement and use of TCs at present. Half of the government initiated TCs (over 500) are not operational today (private communication with ICTA representative).

We argue that the situation could be improved through collaboration between local stakeholders, TC staff and visitors, the government ICT agency (ICTA) and TC organizations, to achieve a sustainable project with local ownership [11] taking into consideration the specific local needs and requirements. Particularly, the underserved populations of tea estate areas might benefit more of the local TCs, if their voices were made stronger in the development process. Estate areas have developed their own particular 
socio-economic and cultural conditions with the imported/migrated Indian Tamil population as the workforce. They have remained isolated and marginalized with limited possibilities for social mobility and development. Due to their particular character, tea estate areas can benefit from a TC as a service provider.

Based on the idea of inclusion and with a specific focus on tea estate areas, an international team of five researchers from the universities of Colombo and Stockholm embarked a research and development initiative to explore the conditions of TC development now that a decade has passed since the commencement of the TC initiative by the Sri Lankan government.

Research questions addressed in this study are: 1) How can participatory methods inform development initiatives in the tea estate context? and 2) What are the particular needs and requirements of the tea estate populations regarding telecentres?

\section{Methodology}

The research and development project addressed in this paper, is framed theoretically and methodologically by participatory approach [13,22] applying a specific methodology of Future workshops consisting of four separate parts: 1) co-inspirational activities; 2) brainstorming sessions; 3 ) applied photo voice sessions, and 4) a final appreciation session with refreshments and a photo show. Our notion of Future workshop is not to be mixed with the one Jungk \& Mullert [12] have introduced in the MDI literature. Our Future workshop has been designed to meet the conditions of a specific setting where the researchers' aim is to maximise the limited resources (time and funding) for a best possible outcome. The design could be described as "quick and dirty" (informing the design process through short, focused study) gathering enough data to initiate a development process with the TC staff and users jointly.

The two-day Future workshop was commenced with co-inspirational sessions with targeted activities for different participant groups in the community. Research team introduced programming through gaming and English language learning sessions with a new mobile application developed at the University of Colombo for the school children and school leavers. We demonstrated the Internet for a group of women and we talked about the possibilities of Wikipedia and Wikiversity for teachers and library personnel.

During photo voice sessions [25, 26], participants took photos of their community using the tablets that we lent them. These photos give a vivid illustration of the community and the neighbourhood. Brainstorming sessions constituted the principal activity in the Future workshops. Participants were urged to come with ideas for further development of TCs. This paper is based mainly on the brainstorming data. Additional data collection was conducted through a questionnaire, participant observations and interviews during the Future workshops.

\subsection{Setting of the Study - Sri Lankan TCs of Tea Estate Areas}

Prior to the study reported in this paper, a reconnaissance trip was made in the tea estate district of Nuwara Eliya to explore the overall present day status of TCs in the area with 
the aim to identify good candidates for further collaboration. Our criteria were to find TCs that were operational in the sense that basic equipment would be in place and that the staff would be interested in collaborating with us.

Our choice fell on two different types of TCs; one government initiated $\mathrm{Ne}$ nasala (TC1) and the other, Thondaman Foundation initiated, e-kiosk, called Prajashakthi (TC2), see Table 1. Our sampling approach followed the idea of purposefulness [19] identifying and selecting information-rich sites that would allow us to examine the situation of TCs in detail, and understand the present conditions of these establishments.

Table 1. TCs in Nuwara Eliya district chosen for the study.

\begin{tabular}{|c|c|c|c|c|}
\hline & Location & Equipment & Activities & Users \\
\hline $\begin{array}{l}\text { TC } 1 \\
\text { (Nenasala) } \\
\text { government } \\
\text { initiated }\end{array}$ & $\begin{array}{l}\text { Small town, } \\
\text { Shared } \\
\text { space with } \\
\text { the local li- } \\
\text { brary }\end{array}$ & $\begin{array}{l}4 \mathrm{PCs} \\
\text { scanner } \\
\text { printer } \\
\text { WiFi-router } \\
\text { No function- } \\
\text { ing Internet } \\
\text { connection }\end{array}$ & $\begin{array}{l}\text { Basic com- } \\
\text { puter courses, } \\
\text { English lan- } \\
\text { guage courses }\end{array}$ & $\begin{array}{l}\text { Mainly school children } \\
\text { A group of moth- } \\
\text { ers/housewives }\end{array}$ \\
\hline $\begin{array}{l}\text { TC } 2 \\
\text { (Prajashakti) } \\
\text { Thondaman } \\
\text { Foundation in- } \\
\text { itiated }\end{array}$ & $\begin{array}{l}\text { Next to a tea } \\
\text { factory, } \\
\text { own build- } \\
\text { ing with } \\
\text { four rooms }\end{array}$ & $\begin{array}{l}4 \text { PCs } \\
\text { scanner } \\
\text { printer } \\
\text { projector } \\
\text { no function- } \\
\text { ing Internet } \\
\text { connection }\end{array}$ & $\begin{array}{l}\text { Basic com- } \\
\text { puter courses, } \\
\text { English lan- } \\
\text { guage courses }\end{array}$ & $\begin{array}{l}\text { Mainly school children } \\
\text { and school leavers }\end{array}$ \\
\hline
\end{tabular}

TC1 manager is not paid for his work, but he is employed by the local governmental body Pradesheeya Sabhaa. He is a former teacher and dedicated to work for the community. He is assisted by the library personnel and the librarians also use the computers in their library work. The TC1 manager has got many ideas of how to develop the activities. His main concern is the lack of resources. He tries to collaborate with another TC in a near-by town but the lack of funds makes it difficult, as he cannot afford compensating any training engagements from the other TC. At present, he relies on collaboration with the library staff and on the voluntary efforts by the local community. For him, the research team and the idea of outside collaboration seems as an opportunity he cannot afford to miss as no other assistance is in sight.

The Prajashakthi type TC 2 receives funding from the "Ministry of up country, new villages, estate infrastructure and community development", for the salaries, and maintenance expenses. However, the Internet costs have not been covered for some time due to the political uncertainties and shift of government. Manager here would also like to offer a wider selection of courses. For example, school leavers would need preparatory courses and even vocational training that would help them widen the range of opportunities after finishing school.

Both TCs share the problems with insufficient resources and the lack of functioning Internet connection. Both TC managers recognize the need for further training for the $\mathrm{TC}$ staff as a first and crucial step in their development plans, and they both are eager 
to develop the services for their communities. Against this background, the international research team initiated a collaboration to plan for new activities that would engage both the TC staff and the local community for further development of their TCs.

\subsection{Participants}

For recruiting participants for the Future workshops, the research team relied on the TC managers who made the invitations in their communities. Table 2 provides a summary of the participants.

Table 2. Participants of the Future workshops.

\begin{tabular}{|l|l|l|l|l|l|l|}
\hline & Gender & & Age & & Language & \\
\hline & Female & Male & Children & Adults & Tamil & Sinhala \\
\hline TC1 & 19 & 11 & 13 & 17 & 22 & 8 \\
\hline TC2 & 23 & 14 & 37 & & 37 & \\
\hline Total & $\mathbf{4 2}$ & $\mathbf{2 5}$ & $\mathbf{5 0}$ & $\mathbf{1 7}$ & $\mathbf{5 9}$ & $\mathbf{8}$ \\
\hline
\end{tabular}

Majority of the children were those at school, another group consisted of school leavers who had just finished their O-levels and waiting for the results of the examination. In addition, small children not at school yet, were present during the days drawn by curiosity to the TC to see the visitors. The group of adults represented various vocational groups, such as teachers, librarians, office workers, and police as well as housewives. Our sample could thus be described as a combination of chain sampling and mixed purposeful sampling [19], not representative of the whole community, but fairly representative of the TC users as school children constituted the majority of the participants in the study. As the TC managers were our key informants and most likely used their own networks to invite participants, those who actually showed up during the Future workshops were either typical visitors to the TCs, or potential visitors, and interested ones with motivation for TC development.

\subsection{Brainstorming Sessions and Questionnaire}

For the purpose of defining a baseline understanding of the participants, a questionnaire with 10 questions was conducted among them by the research team during the first day of the Future workshop. In addition to basic background information about the participants (gender, age, occupation, first language), the questionnaire covered questions about the media ownership and use as well as TC use.

The main activity during the Future workshops was brainstorming sessions for collecting ideas and concrete suggestions for improvements of the TCs. The research team was also keen to learn more about the understandings of the participants in relation to the use of TCs. Third central aspect was the importance of drawing attention to active participation and ownership of the TCs. 
Participants were asked to respond to two questions: 1) What can you do for the TC? and 2) What can the TC do for you? With these two questions we wished to capture the reciprocity in the relationship: a TC is not only a place where the community members can receive services. Equally important is to plan how the community members can contribute to their TC. The theme of reciprocity emerged during our conversations with the TC managers prior to the awareness raising activity. They complained that the community members saw the TC as a government service provider that should be free of charge.

Participants were divided into small groups of five and given a large sheet of paper and a pen for documentation of their thoughts and ideas. After half an hour of group work, the results of each group were presented and discussed in plenum. All the ideas were collected on a large sheet of paper for everyone to see the results. These papers were photographed and transcribed by the research team for later analysis.

Qualitative data from the Future workshops was analysed through a systematic, thematic analysis [2] applying MAXQDA. This analysis was conducted with focus on the specific research questions, with a data-driven approach where the coding was done without a pre-existing coding framework. Furthermore, the analysis focused not only on describing but also interpreting the data, resulting in latent rather than semantic themes (ibid.). The questionnaire has been quantitatively processed.

\section{$3 \quad$ Findings}

\subsection{Questionnaire Results}

Table 2 summarizes basic information about the participants. At TC 1, almost all of the children visit the TC at least once a week. At TC 2, half of the participants visit TC frequently and one third was there for the first time.

Most participants have a TV and radio at home. At TC 1,60\% have a computer at home, compared to $30 \%$ at TC 2; however, only half of all these possess Internet connection at home (excluding smartphone connection). Many young people at TC 2 share a mobile phone with their families, while adults at TC 1 have their own devices. $70 \%$ of all participants at TC 1 have a smartphone, versus $24 \%$ at TC 2 . Phones are used mainly for making voice calls and for text messaging. Attending computer or English language classes are the main reasons for visiting TCs. Some of the young also come for entertainment like gaming. Adults rely on the TC for other services like scanning and copying documents. Social media, like Facebook, YouTube, and Twitter, are mostly known by the name without real understanding of what they represent. Results from the questionnaire confirm that access to ICTs and training digital literacy are needed as the ownership of mobiles is often a shared one and availability to computers and the Internet is limited. 


\subsection{Findings from the Brainstorming Sessions}

Analysis of the brainstorming results shows two main themes: 1) 'Needs' of the participating community members; and their 2) 'Relations to the TC'. Under the category 'Needs' we found three main subcategories: 'ICT education'; 'ICT for education', and 'More Resources'. Under the category of 'Relations to the TC', following two themes emerged: partly the brainstorming participants were discussing their understanding of TC ('Notions of TC') and partly we could distinguish an emergent 'Sense of community' which was expressed in various ways.

\subsubsection{Needs - What is Lacking in the TCs?}

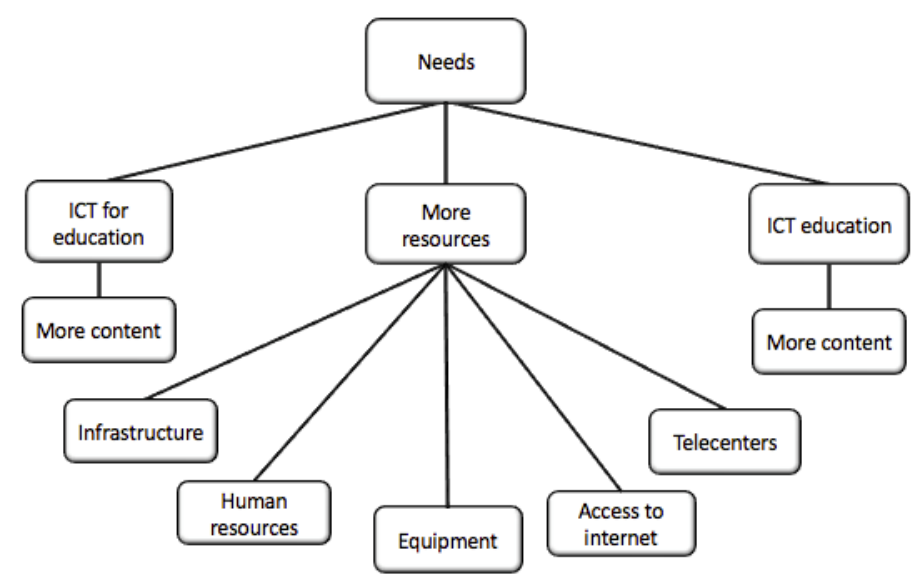

Fig. 1. Conceptual map of needs.

TCs were mainly understood as places for educational activities. This understanding is based on the principal experience of these places, but reflects also the central need in the community: educational opportunities are scarce and thus there is a need to learn more about ICTs as such and as a vehicle for further studies, as well as there is a need to learn English language as a preparation for further education. Thus, it is understandable that needs explicated by participants focused on improvement of the educational facilities. In the same line of reasoning, another central aspect of improvement expressed during the brainstorming was human resources; the need for more qualified teachers and continuous service to the community.

The need for more computers, more class room space and more teachers was expressed by all. The existing 4 stationary PCs and one laptop (for the instructors) are not sufficient for conducting classes for bigger groups. Children were also specific about the need for more in-depth and up-to-date knowledge about the technological development. They want to have good Internet connection and download games. Courses in web design, graphics, and game development are also in their wish list. The school 
leavers are also keen to receive more education and information about the possibilities that exist for them. They also note that it would be important to educate parents about the relevance of free services at the TC, in contrast to the private and expensive classes in the city.

Another important aspect that the participants brought up is the lack of materials in Tamil, the first language of these communities. Dictionaries (hardcopy) of computer vocabulary from English and software manuals (hardcopy) in Tamil, e.g. about image editing were listed as crucial educational material required in TCs. It may be noted that one of the TCs had received a translation device, but it was not in use due to lack of batteries.

For the participating women the offerings of the telecentre were not sufficient. " $T C$ should contribute with different services to the community" and there should be "more useful things to women". Employability and communication are major concerns:

"I have my sister working in the Middle East, I would have loved to learn how to Skype, so I can let her know her children are well cared." Woman 1

"I like to go there and learn how to use the Internet and improve my English so I can get a better job in the Middle East." Woman 2

"We have relatives in India they are well connected to the Internet we would like to look for possibilities to do business but I am reluctant to go there as the place is run mainly for young people. So I send my kids perhaps they can teach me one day." Woman 3

Women also point out that there should be several TCs in these remote areas as transportation is troublesome and time consuming in the winding, steep roads of the hill country.

\subsubsection{TCs and the Sense of Community}

Prior to the workshop activities, the TC managers had complained that the local community does not regard the TC as 'theirs' but rather as a government service. Against this background, it is interesting to note that all the workshop participants formulated expressions of social responsibility toward the TC. They stated a need to take care of their TC; they viewed it as their property to be protected and maintained. In addition, they claimed a new goal of making "the best TC in the world". The adults also proposed to create funding for the teachers as a community effort, a clear indication of the emergent sense of community involvement.

The mothers and other adults became quite enthusiastic about promoting TCs in their own community: "We could go the schools here and talk about TCs and the services it provides". They also suggested a "Nenasala club" as a way of gathering members of the community around the TC to support it in various ways, even economically; today the TC1 instructors work for free. The Nenasala club can also be related to a "megameeting" envisioned at $\mathrm{TC} 2$, to gather users once a year with other TCs to share knowledge and create a regional network of TCs and their users. Another suggestion was to build a social media community of TC users in order to strengthen the geographically isolated TCs. 


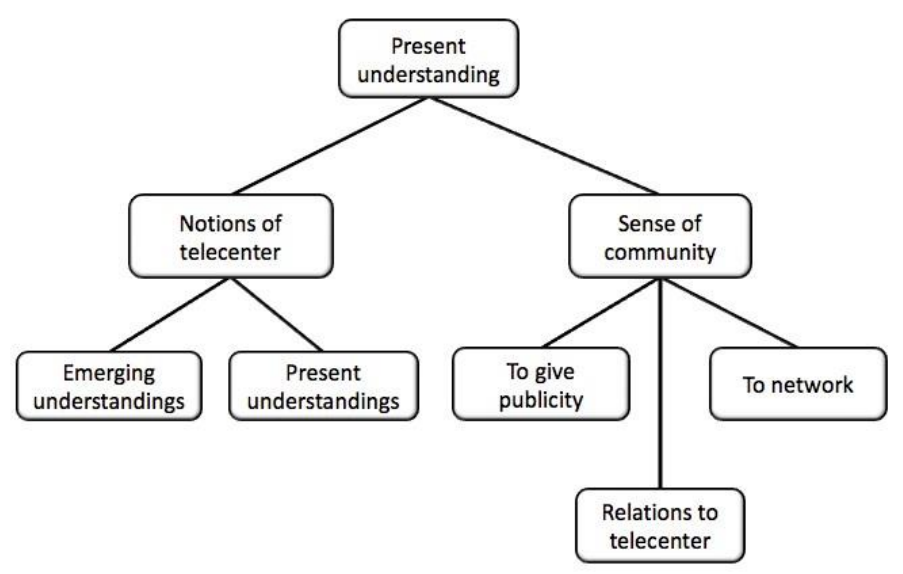

Fig. 2. Conceptual map of the notion of TC and community.

Children were also ready to "Make their TC the best one in the world" and "Arrange competitions in ICT use to increase motivation among children to study harder". There is a sense of pride and ownership in statements like: "I will tell others about the TC and what is going on in the TC"; "We will do our best, listen carefully in order to learn, and use the resources wisely."; "We will maintain the TC clean, tidy".

We can record how the notion of TC was expanded by the participants from a sole ICT access and training centre into a place with multiple functions. The idea of using the TC as a place for knowledge sharing on issues relevant for the community suggests this. Expressions like "a good place to spend time" and "communicate with people outside the area" indicate that the participants are beginning to realise the potential of the TCs as social places where they can come to meet others and for example play games. Further, adults showed a great enthusiasm once they realized how ICTs could be used in various ways. For example, as women were taught about social media, they realised the potential of it in their own lives and came up with ideas of applying social media for their businesses. One of the teachers in the participant group wanted to develop an ICT curriculum for her nursery class when she realised she could receive support in the TC. Thus, the idea of TC as a resource centre was starting to take form.

\section{Discussion}

Our point of departure, based on action research tradition, has been the conviction that sustainability of a TC requires active participation of the local community, which has been lacking in much of ICT4D research $[10,14]$. By engaging two TCs and their users in development activities, we have discovered that the present offerings of these TCs are inadequate and not meeting the specific needs of the community. The choice of two TCs with different financial arrangements, and different geographical locations (one in 
a small town, the other next to a tea factory) was deliberate to examine whether these differences play any role in the way TCs are functioning. It is evident that despite the differences, they share many issues regarding the TC operations: Lack of network and hardware resources, absence of well-trained instructors, and limited hours for training being the most crucial ones according to the brainstorming results. Also, the absence of community involvement is mutual.

The state of TCs in the tea estate areas demonstrate how digital divide cannot be erased by simply bringing in some technology. We believe that only through engaging the community in digital literacy projects that are intimately connected to the local context and the specific needs and requirements there, a real transformative change can be commenced. As Breitenbach [3] notes: "People need to and want to be informed in order to be able to take part in their own development - to become part of the information society". Raising awareness becomes an essential part in community ownership as people need to be aware of what they can do for the TC and what they can get from the TC by actively involving in TC activities. In the brainstorming session, several ideas of social engagement were presented, like creating a TC club; organising TC megameetings; supporting the TC financially; and taking care of the property in a responsible way so that the community could be proud of the TC. All these ideas reflect a budding sense of community awareness of possibilities related to TCs as instruments for local development $[8,11]$ and change. This shows that community ownership is a possible way of establishing sustainable TCs with focus on targeted community based services. Based on our findings, we believe that Future workshops may function as a catalyst to this participative process. However, development and transformation requires a longitudinal engagement as has been pointed out repeatedly in the development discussions [3].

The information and knowledge that was produced during the brainstorming are well grounded in the needs and requirements of the participants and their families giving expression to wishes that would provide the TC with the very basic resources for ICT and language training. Notable is the lack of ideas for economic development. Women expressed some ideas in this direction but as studies $[3,16]$ suggest, development should not be based exclusively on educational offerings but need to be combined with economic development initiatives that can enhance employability in the community. This is crucial in tea estate areas where economic opportunities are scarce, tea industry being the main source of income.

Even though this study was fairly small and limited in a specific context, it demonstrates how knowledge and awareness can be co-created through collaborative methods. During Future workshops the participants have shown their willingness to take ownership of their local TCs, but at present, mechanisms to initiate ownership are missing, which is why we suggest that Future workshops can function as such a mechanism. The method may be applied during a longer period of time in conjunction with a set of supportive activities. As the TC managers pointed out: several occasions and a longer period of time would be more suitable to attract different groups in the community to initiate more profound conversations about the development work. 


\section{$5 \quad$ Conclusions and Future Work}

Our findings suggest that for a sustainable development of TCs following measures should be considered to meet the specific local needs and requirements:

- A substantial expansion of course offerings, equipment and human resources to meet the needs of the local population while creating a sufficient and functional study environment

- Targeted competence development activities (both digital literacy and vocational training) for women and school leavers to support employability

- Create a proper systematic approach to commence community ownership

- Consider economic development as an essential part of the TCs and raise awareness of the economic opportunities through TCs

- A locally operational supportive network for the TC staff for resource sharing and competence development

- Learning and technical instruction materials in Tamil language

It is evident that an active community around TCs is required and that different services and interactions for diverse groups of people in the society are needed in the TC for it to become attractive. A move from one purpose (ICT training) TC to multipurpose (innovations, entrepreneurship) TC is vital.

Even though the community might be willing to provide financial support to the TC and thus enhance the quality of the services, TCs need alternative means of income to ensure financial stability. Further, TCs need to develop strategies on how to eliminate infrastructure barriers of connectivity and ways to strengthen the competences of the TC instructors. These may be realized through private sector partnerships.

The continuation of our project contains of supporting activities. TC 1 is in the process of expanding the number of courses offered. The research team organises occasional training sessions through Skype-based communication. We have also sponsored the TC with an Internet subscription, and the TC is examining crowdfunding options for financial support.

\section{References}

1. Avgerou, C.: Discourses on ICT and Development. Inf. Technol. Int. Dev. 6, 3, 1-18 (2010).

2. Braun, V., Clarke, V.: Using thematic analysis in psychology. Qual. Res. Psychol. 3, 2, 77101 (2006).

3. Breitenbach, M.C.: Telecentres for sustainable rural development: Review and case study of a South African rural telecentre. Dev. South. Afr. 30, 2, 262-278 (2013).

4. Davison, R.M. et al.: Information Systems in Developing Countries: Theory and Practice. City University of Hong Kong Press (2005).

5. Department of Census and Statistics: Sri Lanka Labour Force Survey Annual Report - 2015. (2015).

6. Gomez, R.: When You Do Not Have a Computer: Public-Access Computing in Developing Countries. 20, 3, 274-291 (2014). 
7. Hanna, N.K.: E-Transformation as an Integrating Strategy. In: Hanna, N.K. and Knight, P.T. (eds.) Seeking Transformation Through Information Technology, Innovation, Technology, and Knowledge Management. pp. 1-19 Springer (2011).

8. Hanna, N.K.: Mastering Digital Transformation: Towards a Smarter Society, Economy, City and Nation. Emerald Group Publishing Limited (2016).

9. Harris, R.W.: Explaining the Success of Rural Asian Telecentres. In: Information Systems in Developing Countries: Theory and Practice. pp. 83-100 University of HK Press, Hong Kong (2005).

10. Harris, R.W.: How ICT4D Research Fails the Poor. Inf. Technol. Dev. 22, 1, 177-192 (2016).

11. Heeks, R.: The ICT4D 2.0 Manifesto: Where Next for ICTs and International Development? (2009).

12. Jungk, R., Mullert, N.: Future workshops: How to Create Desirable Futures. Institute for Social Inventions, London (1987).

13. Kemmis, S., McTaggart, R.: Participatory Action Research: Communicative Action and the Public Sphere. In: The Sage handbook of qualitative research (3rd ed.). pp. 559-603 Sage Publications (2005).

14. Loh, Y.A.: Approaches to ICT for development (ICT4D): vulnerabilities vs. capabilities. Inf. Dev. 31, 3, 229-238 (2013).

15. Malek, J.A. et al.: Symbiotic relationship between telecentre and lifelong learning for rural community development: A Malaysian experience. Turkish Online J. Educ. Technol. 13, 3, 148-155 (2014).

16. Mamba, M.S.N., Isabirye, N.: A Framework to Guide Development Through ICTs in Rural Areas in South Africa. Inf. Technol. Dev. 21, 1, (2015).

17. Mbatha, B.: Pushing the agenda of the information society: ICT diffusion in selected multipurpose community telecentres in South Africa. Inf. Dev. 1-16 (2015).

18. Miller, P.B.: From the Digital Divide to Digital Inclusion and Beyond: Update on Telecentres and Community Technology Centers (CTCs). SSRN Electron. J. 2011, (2013).

19. Patton, M.Q.: Qualitative Research \& Evaluation Methods: Integrating Theory and Practice. Sage Publishing, Thousand Oaks, Calif. (2015).

20. Peiris, R. et al.: Bridging the Digital Divide in Sri Lankan Tea Estate Areas. In: Nielsen, P. (ed.) Proceedings of IFIP 9.4 13th International Conference on Social Implications of Computers in Developing Countries. pp. 773-784 (2015).

21. Rahman, T., Bhuiyan, S.H.: Multipurpose community telecenters in rural Bangladesh: A study of selected Union Information and Service Centers. Inf. Dev. 32, 1, 5-19 (2014).

22. Reason, P., Bradbury, H.: Handbook of Action Research. SAGE, Los Angeles (2006).

23. Shadrach, B.: Nenasala The Sri Lankan Telecentre Experience. Information and Communication Technology Agency, Colombo (2012).

24. Singh, J.P., Flyverbom, M.: Representing participation in ICT4D projects. Telecomm. Policy. 40, 7, 692-703 (2016).

25. Wang, C.: Photovoice: A participatory action research strategy applied to women's health. J. Women's Heal. 8, 2, 185-192 (1999).

26. Wang, C., Burris, M.A.: Photovoice: Concept, Methodology, and Use for Participatory Needs Assessment. Heal. Educ. Behav. 24, 3, 369-387 (1997). 